\title{
Gender Difference in Preferences for Second Language Vocabulary Learning Strategies: A Pilot Study
}

\author{
Chi Wui NG
}

\author{
Department of English- The Chinese University of Hong Kong- Hong Kong- China \\ ngchiwui@1ink. cuhk. edu. hk
}

\begin{abstract}
Vocabulary learning strategies play an indispensable role in assisting foreign language learners in expansion of their lexicon albeit efficaciousness of each strategy largely contingent upon preferences of individual learners. The present pilot study aims at investigating gender difference in preferences for second language vocabulary learning strategies. Self-report questionnaires on frequency of usage of distinct vocabulary learning strategies were distributed to 15 Thai learners of English at tertiary level. Male students were discovered to employ form-focused strategies as well as metacognitive monitoring and evaluation strategies more frequently whilst female students were found to adopt meaning-focused cognitive strategies and metacognitive planning strategies more frequently than their counterparts do. Such gender difference may illuminate instruction on vocabulary learning strategies in foreign language classrooms by encouraging teachers to take gender of students into consideration whilst planning vocabulary lessons in a bid to maximize pedagogical efficacy.
\end{abstract}

Keywords: vocabulary learning strategies, second language acquisition, gender

\section{Introduction}

Constituting the most fundamental level of the grammatical hierarchy, words lay the basis of higher organizational levels of language; vocabulary learning is thereby widely construed as the crux of language learning (Ellis,2006, Nelson,1998). The lexicon of any language comprising innumerable items, by no means is it plausible for learners to learn the entirety of the vocabulary, in particular low-frequency words, from teachers; it is thereby not uncommon for them to engage in self-directed vocabulary learning by resorting to multifarious vocabulary learning strategies, which denote attempts deliberately made by learners to enhance efficaciousness in vocabulary learning (Nation, 2013). Having consulted vocabulary reference books and surveyed vocabulary learning practice of Japanese learners of English, Schmitt(1997) compiled an inventory of 58 vocabulary learning strategies prevalently employed by foreign language learners and devised a taxonomy dividing identified strategies into five categories: determination strategies, social strategies, memory strategies, cognitive strategies, and metacognitive strategies (see Schmitt, 1997 for detailed explanation of each category).

Whilst vocabulary learning strategies lay an indispensable role in vocabulary learning, efficaciousness of each category of strategies is largely contingent upon preferences of individual learners. Building upon the taxonomy developed by Schmitt, the present pilot study, which capitalizes upon the research design of survey research and involves Thai learners of English at tertiary level, aims at investigating gender difference in preferences for second language vocabulary learning strategies and is intended to illuminate instruction on vocabulary learning strategies in foreign language classrooms by encouraging teachers to take gender of students into consideration whilst planning vocabulary lessons in the future in a bid to maximize pedagogical efficacy. 


\section{Literature Review}

Since the advent of transformative learning in the 1970s, vocabulary learning strategies, which are subsumed under language learning strategies, have received escalating attention from educationalists and applied linguists, effectuating an expanding body of research on such an area of study. Earlier research predominantly zeroed in on comparisons amongst myriads of strategies in terms of their efficacy in discovery and consolidation of the form, meaning, and use of vocabulary (Schmitt, 1997). Strategies requiring shallower processing like rote memorization were discovered to be more pervasively adopted by foreign language learners than those necessitating cognitive processing like construction of semantic maps (Cohen \& Aphek, 1981; O’Malley, Chamot, StewnerManzares, Kupper, \& Russo, 1985). On the face of it, the latter were contended to be more favourable to retention of vocabulary than the former (Ahmed, 1989; Cohen \& Aphek, 1981; Craik \& Tulving, 1975; Pressley, Levin, \& Miller, 1982), which concurred with the Involvement Load Hypothesis put forward by Hulstijn and Laufer (2001); all the same, more detailed explanatory studies subsequently conducted pointed out that barely could any vocabulary learning strategies be construed as inherently desirable, but any strategy could be productive as long as leaners held positive attitude to it (Chamot \& Rubin, 1994; Politner \& McGroarty, 1985; Wenden, 1987). The focus of research has thereby been shifted to correlations between learners' preferences for vocabulary learning strategies and distinct variables, one of which is gender.

Many a study has been conducted to examine gender difference in preferences for second language learning strategies (Oxford 1993a, 1993b). Female learners have been discovered to possess stronger preferences for social strategies, formal rule-based strategies, and metacognitive strategies whilst their male counterparts have been found to favour visual strategies (Ehrman \& Oxford, 1989; Oxford, 1989; Oxford, Nyikos, \& Ehrman, 1988; Zoubir-Shaw \& Oxford, 1995); these findings can be attributable to disparities in social orientation, linguistic development, and learning styles between the two genders. Possessing a tendency to encourage turn-taking in conversations and yearning for social approval, women are alleged to possess greater interests in social activities and eagerness to take charge of their learning through self-management in compliance with social norms respectively when compared to men (Bardwick, 1971; Lakoff, 1975; Maccoby \& Jacklin, 1974); usage of social and metacognitive language learning strategies is thereby more frequent amongst females (Ehrman \& Oxford, 1989; Politzer, 1983). Moreover, corroborated to surpass men in verbal ability out of more intimate connections between the left and right hemispheres of the brain, women are born with an innate advantage in mastery of formal rule-based language learning strategies (Ellis et al., 2008; Green \& Oxford, 1995; Oxford \& Nyikos, 1989). In contrast, attributed to men's outperformance over females in visual-spatial skills, visual learning experience is probably more profitable to males; this accounts for their stronger desire for language learning strategies associated with images (Nyikos, 1987; Reid, 1987). The aforementioned gender differences are deemed to be substantially influential in efficacy of disparate strategies with respect to the two genders.

For all extensive research on gender difference in preferences for second language learning strategies, only has one formal study drawing connections between vocabulary learning strategies and gender been conducted. Making comparisons between the number and range of vocabulary learning strategies utilized by male and female Spanish learners of Basque and English, Catalan (2003) found females' considerable usage of formal rule strategies, input elicitation strategies, rehearsal strategies, and planning strategies as well as males' sheer usage of image strategies in vocabulary learning; such findings largely complied with those of literature on gender difference in preferences for language learning strategies. That said, only did that questionnaire-based study involve respondents' indication of whether normally applying certain strategies with their frequency of usage kept out of consideration, so it was argued to fail to provide a comprehensive picture of gender difference in preferences for vocabulary learning strategies. For this reason, further research 
taking learners' frequency of usage of vocabulary learning strategies has to be conducted in a bid to complement Catalan (2003)'s study; this provides motivation for the current study. question:

In particular, the present research is intended to respond to the following research

\section{Does gender difference exist in frequency of usage of second language vocabulary learning strategies?}

With reference to previous studies concerning gender difference in preferences for second language learning strategies, it is predicted that female learners employ social strategies, formal strategies, and metacognitive strategies more frequently than their male counterparts do in the process of vocabulary learning, and more frequent usage of visual strategies is anticipated to be observed amongst male learners. On the basis of these predictions, it is further hypothesized that female learners possess stronger preferences for social, formal, and metacognitive vocabulary learning strategies whereas male learners prefer visual ones more.

\section{Methodology}

The current pilot study chiefly aiming at eliciting learners' vocabulary learning practice, data were collected by means of a self-report questionnaire, which comprised three parts (see Appendix). Questionnaires were distributed to seven male and eight female Thai tertiary students attending a sixweek English language enhancement course in a British university.

Designed in accordance with a five-point Likert scale with one and five representing "never" and "always" respectively, questions in the first part of the questionnaire required respondents to indicate their frequency of usage of each second language vocabulary learning strategy in the course of learning English vocabulary. Only had two to three strategies reported to be most frequently adopted by foreign language learners from each of the five categories in the taxonomy compiled by Schmitt (1997), which constituted a total of 13 strategies, been incorporated into the questionnaire lest respondents' responses be profoundly influenced by a fatigue factor and cluster around average scores by virtue of a lengthy questionnaire.

The first part of the questionnaire played the overriding role in collecting data of the dependent variable of the study whilst the two remaining parts were designed to assemble data of the independent variable and probe into impacts on findings of the study exerted by confounding variables. Identified to be correlated with learners' strategy use, learners' vocabulary size was regarded as an overarching confounding variable (Fan, 2003; Gu \& Johnson, 1996). The second part of the questionnaire was intended to elicit respondents' vocabulary size via a vocabulary size test created by Beglar and Nation (2007); two questions from each of the levels one to ten were selected on a random basis, constituting a total of 20 questions. The final part of the questionnaire was designed to collect information of respondents' gender, age, and socioeconomic background, the former two of which were elicited directly whereas socioeconomic background was elicited indirectly via parents' education levels.

\section{Results}

In response to the research question, collected data were analyzed both descriptively and inferentially. Differences in frequency of usage of second language vocabulary learning strategies between male and female students were tested with two-tailed independent-samples t-tests, and power analyses were conducted for the sake of uncovering statistical power of the findings; results of statistical analyses are presented in Table 1. 
Table(1): Summary Statistics of Frequency of Usage of Second Language Vocabulary Learning Strategies

\begin{tabular}{|c|c|c|c|c|c|c|c|}
\hline Strategies & $95 \% \mathrm{CI}$ & $\begin{array}{l}\text { Mean of male } \\
\text { students (SD) }\end{array}$ & $\begin{array}{l}\text { Mean of } \\
\text { female } \\
\text { students (SD) }\end{array}$ & t-value & p-value & $\begin{array}{l}\text { Effect } \\
\text { size }\end{array}$ & Power \\
\hline \multicolumn{8}{|l|}{ Determination strategies } \\
\hline Bilingual dictionary & $-.76,1.33$ & $4.29(.76)$ & $4.00(1.07)$ & .59 & .57 & .34 & .08 \\
\hline $\begin{array}{lll}\begin{array}{l}\text { Guess from } \\
\text { context }\end{array} & & \text { textual } \\
\end{array}$ & $-.98, .98$ & $4.00(.82)$ & $4.00(.93)$ & .00 & 1.00 & .00 & .03 \\
\hline \multicolumn{8}{|l|}{ Social strategies } \\
\hline $\begin{array}{l}\text { Ask classmates for } \\
\text { meaning }\end{array}$ & $-1.04, .86$ & $3.29(.49)$ & $3.38(1.06)$ & -.20 & .84 & .13 & .04 \\
\hline $\begin{array}{l}\text { Interact with native } \\
\text { speakers }\end{array}$ & $-.91, .80$ & $3.57(.79)$ & $3.63(.74)$ & -.14 & .89 & .10 & .04 \\
\hline \multicolumn{8}{|l|}{ Memory strategies } \\
\hline $\begin{array}{l}\text { Study the spelling of a } \\
\text { word }\end{array}$ & $-1.01, .65$ & $3.57(.54)$ & $3.75(.89)$ & -.46 & .65 & .34 & .08 \\
\hline Study the sound of a word & $-.24,1.99$ & $4.00(.58)$ & $3.13(1.25)$ & 1.70 & .11 & .92 & .35 \\
\hline Image word's meaning & $-.82,1.71$ & $3.57(1.40)$ & $3.13(.84)$ & .76 & .46 & .33 & .08 \\
\hline \multicolumn{8}{|l|}{ Cognitive strategies } \\
\hline Written repetition & $-.24,2.31$ & $3.29(1.50)$ & $2.25(.71)$ & 1.75 & .10 & .76 & .26 \\
\hline Verbal repetition & $-.56,1.49$ & $3.71(.76)$ & $3.25(1.04)$ & .98 & .35 & .56 & .16 \\
\hline Take notes in class & $-2.04, .68$ & $3.57(.98)$ & $4.25(1.39)$ & -1.08 & .30 & .47 & .13 \\
\hline \multicolumn{8}{|l|}{ Metacognitive strategies } \\
\hline $\begin{array}{ll}\text { Use } & \text { English-language } \\
\text { media } & \\
\end{array}$ & $-1.24,-.02$ & $4.00(.58)$ & $4.63(.52)$ & -2.21 & $.05 *$ & 2.10 & .95 \\
\hline $\begin{array}{l}\text { Continue to study word } \\
\text { over time }\end{array}$ & $-.50,1.18$ & $3.71(.95)$ & $3.38(.52)$ & .88 & .40 & .56 & .16 \\
\hline $\begin{array}{l}\text { Testing oneself with word } \\
\text { tests }\end{array}$ & $-.67,1.24$ & $3.29(.76)$ & $3.0(.93)$ & .65 & .53 & .41 & .11 \\
\hline
\end{tabular}

Note. CI, confidence interval; SD, standard deviation; p, level of significance; significant at the *p $\leq$ 0.05 level.

Scarcely does gender difference exist in frequency of usage of an overwhelming majority of second language vocabulary learning strategies under investigation; this is substantiated by large pvalues ( $p>.05$ ) of mean differences of all strategies save the strategy of using English-language media. That said, other statistical figures have to be taken into account for more elaborate analyses of gender difference in frequency of usage of those strategies.

First and foremost, a high frequency of usage of determination strategies by both male and female students is evidently observed; this is exhibited by high mean scores (above 4) of the two determination strategies for both genders. However, small effect sizes $(d<.2)$ of mean differences of those two strategies signify negligible gender difference in their frequency of usage. Neither does any significant gender difference exist in frequency of usage of social strategies as shown by small effect sizes $(\mathrm{d}<.2)$ of mean differences.

Concerning memory strategies, small effect sizes $(\mathrm{d}<.4)$ of mean differences of the strategies of studying the spelling of a word and imaging word's meaning reveal insignificant gender difference in frequency of usage of those two memory strategies. Nevertheless, a combination of a large effect size $(\mathrm{d}=.92)$ and small power $(.35)$ of the mean difference of the strategy of studying the sound of a word appears to suggest that male students utilize this memory strategy more frequently than female students do albeit the small sample size of the study has limited the statistical power of the finding, yielding a non-statistical mean difference.

Similarly, medium effect sizes $(.4<\mathrm{d}<.8)$ along with small power $(<.3)$ of mean differences of all three cognitive strategies demonstrate a plausibility that gender difference in frequency of usage of the three strategies is indeed significant yet non-statistical merely on account of the limited sample size. More specifically, it is probable that male students apply the strategies of written repetition and verbal repetition, both of which are form-focused rehearsal strategies, more frequently than female students do whilst female students employ the strategy of taking notes in class, a meaning-focused elaboration strategy, more frequently than male students do. 
Regarding metacognitive strategies, the strategy of using English-language media is the mere strategy under investigation where statistical gender difference in frequency of usage is manifested; a small $\mathrm{p}$-value $(\mathrm{p}=.05)$ and a frightfully large effect size $(\mathrm{d}=2.10)$ provide conclusive evidence for female students' more frequent usage of such a metacognitive planning strategy than that of male students. Despite the absence of statistical gender difference in frequency of usage of the strategies of continuing to study word over time and testing oneself with word tests, which are monitoring and evaluation strategies respectively, medium effect sizes $(.4<\mathrm{d}<.6)$ combined with low power $(<.2)$ of their mean differences probably hint that they are more frequently adopted by male students than female students.

Last but surely not the least, two-tailed independent-samples t-tests were conducted to explore the extent of impacts of the three confounding variables on the findings. An examination of the data indicates no statistical difference in vocabulary size $(p=.64)$, age $(p=.78)$, and parents' education levels $(p=.11, p=.14)$ between male and female respondents, implying that it is unlikely for gender difference in frequency of usage of second language vocabulary learning strategies obtained in the study to be outcomes of discrepancies in those three factors.

On the whole, it appears from statistical analyses that gender difference does exist in frequency of usage of second language vocabulary learning strategies in spite of a lack of statistical mean difference for most strategies under investigation. While male students possess a disposition to utilize form-focused memory and cognitive strategies as well as metacognitive monitoring and evaluation strategies more frequently than their female counterparts do, female students possess a propensity to apply meaning-focused cognitive strategies and metacognitive planning strategies more frequently than their male counterparts do.

\section{Discussion}

Not in sync with findings of previous studies on gender difference in preferences for second language learning strategies in general, the aforementioned findings provide limited evidence in advocacy of predictions made and hypotheses formulated in previous sessions of the paper; this can partially be elucidated by respondents' cultural background as well as educational context.

To begin with, in contrast with previous studies on gender difference in preferences for second language learning strategies, which provided clear evidence for female and male students' preferences for social and visual strategies when compared to their counterparts respectively, the present study exhibits neither statistical nor significant gender difference in frequency of usage of these strategies; this probably results from respondents' one-of-a-kind cultural background, which is significantly influential in their learning preferences and styles. A vast majority of research on gender difference in preferences for second language learning strategies having been conducted in western countries, seldom can their findings be utterly applicable to other educational contexts such as the Asian context, which is characterized by the Confucian culture, a reproductive mode of learning, and teachers' dominance in the classroom (Butler, 2011; Littlewood, 2007; Tang, 2009). In particular, however positive their attitude to English learning is, Thai students, who are respondents of the current study, have been discovered to feel more comfortable receiving knowledge passively in lieu of learning via a communication-oriented approach, displaying a much stronger preference for individual over group learning (Reid, 1987; Swan \& Smith, 2001). Not only do Thai students possess doubts about social learning, they also appear to disfavour visual learning, which has been delineated as one of their minor learning styles (Reid, 1987). Reserved about social learning and visual learning, Thai students, irrespective of their gender, probably possess limited interests in social vocabulary learning strategies, such as asking classmates for meaning, as well as visual ones, videlicet imaging word's meaning; this is a plausible explanation for a lack of statistical or significant gender difference in frequency of usage of these strategies amongst Thai students. 
Besides findings of social and visual vocabulary learning strategies, those of metacognitive strategies are incompatible with predictions made earlier either in that female students' more frequent usage of metacognitive strategies than that of male students were predicted albeit only is female students' usage of some metacognitive strategies found to be more frequent than that of male students in the present study; such findings may be accounted for by respondents' educational context. A high English competence considered one of the determinants paving way for prosperous life in contemporary Thai society, Thai students probably strive to ameliorate their English proficiency by all means (Swan \& Smith, 2001); frequent usage of metacognitive strategies for regulation of one's own learning is thereby no longer limited to female students as postulated. As a matter of fact, students' motivation to facilitate their own language learning via metacognitive strategies has been proposed by Gardner (2001) to hinge upon their language attitude, which varies across individuals. Culture-specific gender difference in language attitude has been investigated in numerous studies (e.g. Kobayashi, 2002; Lai, 2007; Zhang, 2011), yet never has any massive research of such nature been conducted amongst Thai learners of English, effectuating difficulty in providing explanations for findings of the current study. That said, female students' statistically and significantly more frequent usage of English-language media, a metacognitive planning strategy, may be justified in terms of females stronger affection for social media, which has been authenticated in previous studies (Kuppens, 2010). It is reckoned that only through acquisition of better knowledge on gender difference in language attitude amongst Thai learners of English can that in frequency of usage of metacognitive vocabulary learning strategies be more deeply explored.

Added to the above, incongruence between findings of memory and cognitive vocabulary learning strategies of the present study and predictions made is also worthy of discussion. Not only previous research on gender difference in preferences for second language learning strategies (e.g. Green \& Oxford, 1995; Oxford \& Nyikos, 1989) but Catalan (2003)'s study on gender difference in preferences for vocabulary learning strategies also discovered females' more frequent usage of formal rule-based strategies, which was attributable to females' more superior verbal ability when compared to males (Ellis et al., 2008); in contrast, the current study reveals male students' more frequent usage of formal memory and cognitive vocabulary learning strategies, videlicet studying the sound of a word as well as written and verbal repetition, and female students' more frequent usage of the strategy of taking notes in class, a meaning-focused elaboration strategy. Attributed to an enormous mismatch between findings of this study and those of previous ones as well as a lack of sound backing for such extraordinary findings from either a cultural, linguistic, or educational perspective, more research ought to be conducted with an aspiration of delving into reasons behind frequency of usage of those strategies by students of the two genders respectively. Even though it is likely for formulated hypotheses to be falsified by findings of the study, more evidence yielded from research is inevitably required for formulation and verification of new hypotheses.

\section{Conclusion}

Attempting to supplement the body of literature on second language vocabulary learning strategies, the present study aims at investigating gender difference in preferences for second language vocabulary learning strategies by means of self-report questionnaires on frequency of usage of strategies. It can be summarized from results that male students appear to possess stronger preferences for form-focused memory and cognitive strategies as well as metacognitive monitoring and evaluation strategies whereas female students are apt to express stronger preferences for meaning-focused cognitive strategies and metacognitive planning strategies than their counterparts; these findings fail to confirm hypotheses formulated on the onset thanks to specific cultural background and educational context of respondents of the study.

Notwithstanding disagreement between findings of the current study and those of comparable studies conducted in the past, existence of gender difference in preferences for second language 
vocabulary learning strategies is perceived to be a unanimous consensus reached by distinct studies, providing valuable implications for instruction on vocabulary learning strategies in foreign language classrooms. Efficacious usage of vocabulary learning strategies being integral to success in vocabulary learning in a foreign language, instruction on vocabulary learning strategies, which is intended to enhance learners' awareness of strategies and equip them to take control of their own learning, is an indispensable component in foreign language classrooms albeit pedagogical efficacy of such explicit strategy training is reckoned to count largely on learners' attitude to strategies taught (Nation \& Moir, 2008). Should learners possess a strong preference and an immense interest in the strategy introduced by teachers, it will probably be more likely for them to take it seriously and put it into practice more frequently. Existence of gender difference in preferences for vocabulary learning strategies thereby encourages teachers to take preferences of students of distinct genders into consideration in the course of lesson planning and capitalize upon such information to maximize pedagogical efficacy of their instruction.

Precise interpretation of gender difference in preferences for second language vocabulary learning strategies is integral to foreign language teaching, so it is of vital importance for further research to be carried out in response to limitations of the present study; three directions of optimization of the research design are suggested to shed light upon future research. First of all, enlargement of the sample size is necessary to enhance reliability and generalizability of the study. Attributed to the small sample size of the current study, statistical power of mean differences of a large majority of investigated strategies is smaller than 0.2 , implying that the probability that the same conclusion can be drawn from replicated studies is lower than 0.2 . In addition, all respondents being Thai students, findings of the study have been much influenced by the Thai culture, detracting from their generalizability to other learners. Enhancement of the sample size along with recruitment of respondent of distinct nationalities is thereby required to enhance both reliability and generalizability of future studies. Another recommendation is incorporation of the entirety of the list of vocabulary learning strategies into the research, for hardly can gender difference in preferences for discrepant categories of vocabulary learning strategies be understood holistically given that only are two to three strategies selected from each category for investigation. Besides the aforementioned proposals, qualitative analysis is advised to be carried out in future research in complementation of the existing quantitative analysis; this can be achieved through text questions in questionnaires or structured interviews to elicit respondents' language attitude as well as reasons for higher frequency of usage of certain strategies than others. Such qualitative data are opined to be capable of providing valid and concrete explanations for gender difference obtained. It is hoped that research projects with ameliorated design can be conducted to explore the topic in length so that future pedagogical practice can be better informed.

Chi Wui Ng is a Graduate Master in an aided secondary school in Hong Kong as well as a Master's student in applied English linguistics in the Department of English at the Chinese University of Hong Kong. His research interests in the field of applied linguistics are English grammar, second language development, second language instruction, and pedagogical grammar.

\section{References:}

[1] Ahmed, M. O.,Vocabulary learning strategies. In P. Meara (Ed.), Beyond Words, 3-14. London: BAAL, (1989).

[2] Bardwick, J., Psychology of Women: A Study of Biocultural Conflicts. New York: Harper \& Row, 72(9) (1972),1726-1727, https://doi.org/10.1097/00000446-197209000-00064

[3] Beglar, D., \& Nation, I. S. P. (2007). Vocabulary Size Test. Retrieved from http://www.lextutor.ca/ 
[4] Butler, Y. G., The Implementation of Communicative and Task-Based Language Teaching in the Asia-Pacific Region, Annual Review of Applied Linguistics, 31, 36-57(2011), https://doi.org/10.1017/s0267190511000122

[5] Catalan, R. M. J. , Sex differences in L2 vocabulary learning strategies, International Journal of Applied Linguistics, 13 (1)(2003), 54-77, https://doi.org/10.1111/1473-4192.00037

[6] Chamot, A. U., \& Rubin, J., Comments on Janie Rees-Miller's "A Critical Appraisal of Learner Training: Theoretical Bases and Teaching Implications" Two Readers React, TESOL Quarterly, 28(4)(1994),771-6, https://doi.org/10.2307/3587559

[7] Cohen, A. D., \& Aphek, E., Retention of second-language vocabulary overtime: Investigating the role of mnemonic associations. System, 8(3)(1980),221-35,https://doi.org/10.1016/0346$251 x(80) 90004-4$.

[8] Craik, F. I. M., \& Tulving, E., Depth of processing and the retention of words in episodic memory, Journal of Experimental Psychology: General,104(3)(1975), 268-94, https://doi.org/10.1037//0096-3445.104.3.268

[9] Ehrman, M., \& Oxford, R., Effects of Sex Differences, Career Choice, and Psychological Type on Adult Language Learning Strategies, The Modern Language Journal, 73(1)(1989),1-13, https://doi.org/10.2307/327261

[10]Ellis, L., Hershberger, S., Field, E., Wersinger, S., Pellis, S., Geary, D. \& Karadi, K., Sex differences: Summarizing more than a century of scientific research. Mahwah, NJ: Erlbaum, (2008), https://doi.org/10.4324/9780203838051

[11]Ellis, R., Current Issues in the Teaching of Grammar: An SLA Perspective, TESOL Quarterly, 40(1)(2006),83-107, https://doi.org/10.2307/40264512

[12]Fan, M. Y., Frequency of Use, Perceived Usefulness, and Actual Usefulness of Second Language Vocabulary Strategies: A Study of Hong Kong Learners, The Modern Language Journal, 87(2)(2003),222-41, https://doi.org/10.1111/1540-4781.00187

[13] Gardner, R, Integrative motivation and second language acquisition. In Z. Dornyel and R. Schmidt (Eds.), Motivation and second language acquisition (pp. 1-19). Honolulu: Second Language Teaching and Curriculum Centre, (2001).

[14] Green, J. M., \& Oxford, R. A, Closer Look at Learning Strategies, L2 Proficiency, and Gender. TESOL Quarterly, 29(2)(1995), 261-97, https://doi.org/10.2307/3587625

[15]Gu, Y., \& Johnson, R. K., Vocabulary Learning Strategies and Language Learning Outcomes. Language Learning, 46(4)(1996), 643-79, https://doi.org/10.1111/j.1467-1770.1996.tb01355.x

[16] Kobayashi, Y., The Role of Gender in Foreign Language Learning Attitudes: Japanese female students' attitudes towards English learning. Gender and Education, 14(2)(2002), 181-97, https://doi.org/10.1080/09540250220133021

[17] Kuppens, A. H., Incidental foreign language acquisition from media exposure. Learning, media and Technology, 35(1)(2010), 63-85, https://doi.org/10.1080/17439880903561876

[18]Lai, M., Gender and Language Attitudes: A Case of Postcolonial Hong Kong, International Journal of Multilingualism, 4(2)(2007), 83-116, https://doi.org/10.2167/ijm068.0 
[19]Lakoff, R. T., Language and woman's place. New York: Harper \& Row,(1975)..

[20]Laufer, B., \& Hulstijn, J., Incidental vocabulary acquisition in a second language: the construct of task-induced involvement, Applied Linguistics,22(1)(2001),1-26,https://doi.org/10.1093/applin/22.1.1

[21]Littlewood, W., Communicative and task-based language teaching in East Asian classrooms. Language Teaching, 40(3)(2007), 243-249, https://doi.org/10.1017/s0261444807004363

[22] Maccoby, E. E., \& Jacklin, C. N., The Psychology of Sex Differences. Stanford: Stanford University Press, (1974).

[23] Nation, I. S. P., Learning vocabulary in another language (2nd ed.). Cambridge: Cambridge University Press, (2013)

[24] Nation, I. S. P., \& Moir, J. Vocabulary learning and the good language learner. In C. Griffths (Ed.), Lessons from Good Language Learners, pp.159-73, Cambridge: Cambridge University Press, (2008).

[25]Nelson, G., The Internet Grammar of English, (1998)

[26] Nyikos, M. (1987). The effect of colour and imagery as mnemonic strategies on learning and retention of lexical items in German (Unpublished doctoral dissertation). Purdue University, West Lafayette.

[27] O’Malley, J. M., Chamot, A. U., Stewner-Manzanares, G., Kupper, L., \& Russo, R. P., Learning strategies used by beginning and intermediate ESL students, Language Learning, 35(1)(1985), 21-46, https://doi.org/10.1111/j.1467-1770.1985.tb01013.x

[28] Oxford, R. L., Use of language learning strategies: A synthesis of studies with implications for strategy training, System, 17(2)(1989), 235-47, https://doi.org/10.1016/0346-251x(89)90036-5

[29] Oxford, R. L., Instructional Implications of Gender Differences in Second/Foreign Language (L2) Learning Styles and Strategies, Applied Language Learning, 4(1-2)(1993a), 65-94.

[30] Oxford, R. L., La difference continue...: Gender Differences in Second/Foreign Language Learning Styles and Strategies. In J. Sutherland (Ed.), Exploring Gender (pp.140-7). Englewood Cliffs, NJ: Pretice-Hall, (1993b)

[31] Oxford, R., \& Nyikos, M.,Variables Affecting Choice of Language Learning Strategies by University Students, The Modern Language Journal, 73(3)(1989), 291-300,

https://doi.org/10.1111/j.1540-4781.1989.tb06367.x

[32] Oxford, R., Nyikos, M., \& Ehrman, M., Vive la Difference? Reflections on Sex Differences in Use of Language Learning Strategies, Foreign Language Annals, 21(4)(1988), 321-329, https://doi.org/10.1111/j.1944-9720.1988.tb01076.x.

[33] Politzer, R. L., An Exploratory Study of Self Reported Language Learning Behaviors and their Relation to Achievement, Studies in Second Language Acquisition, 6(1)(1983), 54-68, https://doi.org/10.1017/s0272263100000292

[34]Politzer, R. L., \& Mc Groarthy, M., An Exploratory Study of Learning Behaviors and Their Relationship to Gains in Linguistic and Communicative Competence, TESOL Quarterly, 19(1) (1985), 103-123, https://doi.org/10.2307/3586774 
[35] Pressley, M., Levin, J. R., \& Miller, G. E., The keyword method compared to alternative vocabulary-learning strategies, Contemporary Educational Psychology, 7(1)(1982), 50-60, https://doi.org/10.1016/0361-476x(82)90007-8

[36]Reid, J. M., The Learning Style Preferences of ESL Students, TESOL Quarterly, 21(1)(1987), 87-111, https://doi.org/10.2307/3586356

[37] Schmitt, N., Vocabulary learning strategies. In N. Schmitt \& M. McCarthy (Eds.), Vocabulary: Description, Acquisition and Pedagogy, pp. 199-227, Cambridge: Cambridge University Press, (1997)

[38] Swan, M., \& Smith, B., Learner English: A Teacher's Guide to Interface and Other Problems (2nd ed.). Cambridge: Cambridge University Press, (2001)

[39]Tang, E., A Cultural Framework of "Chinese Learn English": a critical review of and reflections on research, English as International Language Journal, 4, 7-13(2009).

[40] Wenden, A., Conceptual background and utility. In A. Wenden \& J. Rubin (Eds.), Learner Strategies in Language Learning, pp. 3-13, Englewood Cliffs, NJ: Prentice-Hall, (1987)

[41]Zhang, B., Gender dissonance in language attitudes: a case of Hong Kong, International Journal of Arts \& Sciences, 4(18)(2011), 77-109.

[42]Zoubir-Shaw, S., \& Oxford, R. L., Gender Differences in Language Learning Strategy Use in University-Level Introductory French Classes: A Pilot Study Employing a Strategy Questionnaire. In C. A. Klee (Ed.), Faces in a Crowd: The Individual Learner in Multi section Courses. Issues in Language Program Direction: A Series of Annual Volumes, pp. 181-213, Boston, MA: Heinle \& Heinle Publishers, (1995)

\section{Appendix \\ An Annotated Questionnaire \\ Questionnaire on Vocabulary Learning}

We are a group of students from the Chinese University of Hong Kong. This questionnaire survey is conducted to better understand gender differences in preferences for vocabulary learning strategies amongst Thai tertiary students. The questionnaire comprises three parts. Please read each instruction and complete all questions. Results of the questionnaire will be used only for research purpose, so please give your answers sincerely. Thank you very much for your help.

\section{Part I}

\section{(Dependent variable: frequency of usage of vocabulary learning strategies)}

In this part, please circle the appropriate number that indicates how frequently you use each of the following strategies or methods while learning English vocabulary.

\begin{tabular}{|l|l|l|l|l|}
\hline 1 & 2 & 3 & 4 & 5 \\
\hline Never & Rarely & Sometimes & Frequently & Always \\
\hline
\end{tabular}

\begin{tabular}{|c|c|c|c|c|}
\hline $\begin{array}{l}\text { 1. I ask my classmates or friends for the meaning of a new word. } \\
\text { Social strategy: ask classmates for meaning }\end{array}$ & 1 & 2 & 3 & 4 \\
\hline $\begin{array}{l}\text { 2. I talk to native English speakers to learn new words. } \\
\text { Social strategy: interact with native speakers }\end{array}$ & 1 & 2 & 3 & 4 \\
\hline $\begin{array}{l}\text { 3. I take notes of new words taught by teachers in English lessons. } \\
\text { Cognitive strategy: take notes in class }\end{array}$ & 1 & 2 & 3 & 4 \\
\hline
\end{tabular}




\begin{tabular}{|c|c|c|c|c|c|}
\hline $\begin{array}{l}\text { 4. I write a word again and again to remember it better. } \\
\text { Cognitive strategy: written repetition }\end{array}$ & 1 & 2 & 3 & 4 & 5 \\
\hline $\begin{array}{l}\text { 5. I remember the meaning of a new word using a picture that shows its meaning. } \\
\text { Memory strategy: image word's meaning }\end{array}$ & 1 & 2 & 3 & 4 & 5 \\
\hline $\begin{array}{l}\text { 6. I study the spelling of a new word. } \\
\text { Memory strategy: study the spelling of a word }\end{array}$ & 1 & 2 & 3 & 4 & 5 \\
\hline $\begin{array}{l}\text { 7. I test myself on words learnt by methods like asking myself their meanings and } \\
\text { pronunciations and using them to form sentences. } \\
\text { Metacognitive strategy: testing oneself with word tests }\end{array}$ & 1 & 2 & 3 & 4 & 5 \\
\hline $\begin{array}{l}\text { 8. I guess the meaning of a new word from surrounding words in a written text. } \\
\text { Determination strategy: guess from textual context }\end{array}$ & 1 & 2 & 3 & 4 & 5 \\
\hline $\begin{array}{l}\text { 9. I check the meaning of a new word by checking its Thai translation from the dictionary. } \\
\text { Determination strategy: bilingual dictionary }\end{array}$ & 1 & 2 & 3 & 4 & 5 \\
\hline $\begin{array}{l}\text { 10. After learning a new word, I continue studying its spelling, pronunciation, and } \\
\text { meaning. } \\
\text { Metacognitive strategy: continue to study word over time }\end{array}$ & 1 & 2 & 3 & 4 & 5 \\
\hline $\begin{array}{l}\text { 11. I learn new English words through English language media like songs, movies, and } \\
\text { news reports. } \\
\text { Metacognitive strategy: use English-language media }\end{array}$ & 1 & 2 & 3 & 4 & 5 \\
\hline $\begin{array}{l}\text { 12. I say a word again and again to remember it better. } \\
\text { Cognitive strategy: verbal repetition }\end{array}$ & 1 & 2 & 3 & 4 & 5 \\
\hline $\begin{array}{l}\text { 13. When I learn a new word, I say it aloud to remember its pronunciation. } \\
\text { Memory strategy: study the sound of a word }\end{array}$ & 1 & 2 & 3 & 4 & 5 \\
\hline
\end{tabular}

Source: Schmitt, N. (1997). Vocabulary learning strategies. In N. Schmitt \& M. McCarthy (Eds.), Vocabulary: Description, Acquisition and Pedagogy (pp. 199-227). Cambridge: Cambridge University Press

\section{Part II}

In this part, please circle the letter with the closest meaning to the key word in each of the questions.

Example

SEE: They saw it.

a. cut

b. waited for

c. looked at

(d.) started

\section{DRIVE: He drives fast.}

a. swims

b. learns

c. throws balls

d. uses a car

3. CIRCLE: Make a circle.

a. rough picture

b. space with nothing in it

c. round shape

d. large hole

5. ROVE: He couldn't stop roving

a. getting drunk

b. travelling around

c. making a musical sound through closed lips

d. working hard

\section{TUMMY: Look at my tummy.}

a. cloth to cover the head

b. stomach

c. small furry animal

d. thumb
2. FIGURE: Is this the right figure?

a. answer

b. place

c. time

d. number

4. PATIENCE: He has no patience.

a. will not wait happily

b. has no free time

c. has no faith

d. does not know what is fair

6. DINOSAUR: The children were pretending to be dinosaurs.

a. robbers who work at sea

b. very small creatures with human form but with wings

c. large creatures with wings that breathe fire

d. animals that lived a long time ago

8. REMEDY: We found a good remedy.

a. way to fix a problem

b. place to eat in public

c. way to prepare food

d. rule about numbers 
9. NUN: We saw a nun.

a. long thin creature that lives in the earth

b. terrible accident

c. woman following a strict religious life

d. unexplained bright light in the sky

11. CAVALIER: He treated her in a cavalier manner.

a. without care

b. politely

c. awkwardly

d. as a brother would

13. DEMOGRAPHY: This book is about demography.

a. the study of patterns of land use

b. the study of the use of pictures to show facts about numbers

c. the study of the movement of water

d. the study of population

15. ECLIPSE: There was an eclipse.

a. a strong wind

b. a loud noise of something hitting the water

c. The killing of a large number of people

d. The sun hidden by a planet

17. OCTOPUS: They saw an octopus

a. a large bird that hunts at night

b. a ship that can go under water

c. a machine that flies by means of turning blades

d. a sea creature with eight legs

19. RUCK: He got hurt in the ruck.

a. hollow between the stomach and the top of the leg

b. pushing and shoving

c. group of players gathered round the ball in some ball games

d. race across a field of snow
10. WEEP: He wept.

a. finished his course

b. cried

c. died

d. worried

12. THRESHOLD: They raised the threshold.

a. flag

b. point or line where something changes

c. roof inside a building

d. cost of borrowing money

14. GIMMICK: That's a good gimmick.

a. thing for standing on to work high above the ground

b. small thing with pockets to hold money

c. attention-getting action or thing

d. clever plan or trick

16. PALETTE: He lost his palette.

a. basket for carrying fish

b. wish to eat food

c. young female companion

d. artist's board for mixing paints

18. HALLMARK: Does it have a hallmark?

a. stamp to show when to use it by

b. stamp to show the quality

c. mark to show it is approved by the royal family

d. Mark or stain to prevent copying

20. MYSTIQUE: He has lost his mystique.

a. his healthy body

b. the secret way he makes other people think he has special power or skill

c. the woman who has been his lover while he is married to someone else

d. the hair on his top lip

Source: Beglar, D., \& Nation, I. S. P. (2007). Vocabulary Size Test. Retrieved from http://www.lextutor.ca/

\section{Part III}

Please provide the following personal information.

Gender:

$\square$ Male $\quad \square$ Female

Age:

(Independent variable: gender)

Faculty:

$\overline{\square \text { Arts }} \square$ Business Medicine $\square$ Science

$\square$ Other (please specify:

Father's Education Level

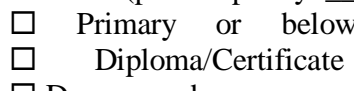

$\square$ Degree or above $\square$ N/A
$\square \quad$ Primary or below

Mother's Education Level Diploma/Certificate

$\square$ Degree or above

$\square$ Education $\square$ Engineering $\square$ Law

$\square$ Social Sciences

N/A

Secondary

Sub-degree

Secondary

Sub-degree

\section{Thank you for your cooperation!}

